\title{
Failure by rats to learn a visual conditional discrimination after lateral peristriate cortical lesions
}

\author{
LUIS GALLARDO, MIRIAM MOTTLES, LUIS VERA, MARIA A. CARRASCO, \\ FERNANDO TORREALBA, VICENTE M. MONTERO, and TERESA PINTO-HAMUY \\ Departamento de Fisiologia y Biofisica, Facultad de Medicina Sede Norte, Universidad de Chile \\ Santiago, Chile
}

\begin{abstract}
Visual functions of lateral peristriate cortex in the gray rat were behaviorally explored. Three groups of rats were trained: normal controls $(\mathrm{N}=6)$, an operated control (monocular field of the striate cortex) $(\mathrm{N}=5)$, and an experimental group which has lesions in the lateral peristriate cortex $(\mathrm{N}=5)$. All subjects were trained postoperatively on a visual conditional discrimination problem. Lateral peristriate subjects had a significant deficit on pattern discrimination with respect to operated and normal control groups, and failed on the conditional discrimination test. Lateral peristriate cortex appears to have an important role in the acquisition of pattern discrimination, and an essential one in more complex visual tasks, where the association of two visual cues is required to master the problem.
\end{abstract}

Electrophysiological studies suggest that the visual cortex of the rat is composed of several peristriate areas in addition to the striate cortex (Montero, 1973; Montero, Rojas, \& Torrealba, 1973). Each of the six peristriate areas has direct and independent connections from the striate cortex (Montero, Bravo, \& Fernandez, 1973). It appears that each peristriate area constitutes a cortical functional unit which processes outputs from the striate cortex.

There is evidence that lesions restricted to the visual cortex in the rat produce deficit in visual pattern discrimination (Bland \& Cooper, 1969, 1970; Braun, Lundy, \& McCarthy, 1970; Lashley, 1931, 1939; Thompson, 1970). However, most previous studies on the effect of visual cortex lesions on visually guided behavior in this animal are based on large removals of the occipital cortex, comprised of different parts of the striate and peristriate cortices.

In order to analyze, at least grossly, the functional deficit that may be provoked by lesions in the lateral peristriate areas, we have placed restricted thermal lesions in the lateral group of peristriate areas. The effect was estimated by a visual conditional discrimination task (Lashley, 1938; North, Maller, \& Hughes, 1958). These authors used triangles as figures (erect vs. inverted) on a black or striped background as discriminanda. Through a series of modifications

This research was supported by NIH Grant NS-12470 and by the University of Chile (Project No. 1450). We thank Drs. J. E. Rose and C. N. Woolsey for helpful comments on the manuscript, R. Roi and S. Hunsaker for the photographic work, and S. Borgner for the typing. along the experimental procedure, they concluded that rats could reverse their responses to the figures and that this was determined by the character of the background. Thus, we thought that this problem might give us information about pattern discrimination (figure components), and at a second stage (critical trials of the conditional task) would serve as an indication of their capacity to associate figure and background elements.

\section{METHODS}

\section{Subjects}

Sixteen naive male gray rats, AXC strain, with an average weight of $250 \mathrm{~g}$ and about 5 months old, were used. Throughout the training phase, all subjects were maintained at $85 \%$ of their free-feeding weights. Water was supplied ad lib.

\section{Apparatus}

Testing was conducted on a Lashley jumping stand, modified by Sutherland and Mackintosh. Detailed description of the apparatus may be found elsewhere (Sutherland \& Mackintosh, 1971).

\section{Pretraining}

\section{Procedure}

The subjects were shaped to jump over a distance of $14 \mathrm{~cm}$ to one of two platforms, each of which had a door bearing a gray card. Every jump was reinforced with a 45-mg Noyes food pellet.

\section{Preoperative training.}

In order to assess the normal performance, all subjects were trained to discriminate between two cards $(14 \times 17 \mathrm{~cm})$, one bearing a vertical, the other a horizontal white bar $(10 \times 2 \mathrm{~cm})$, on a black background. A random stimulus order was used. A session consisted of 20 trials. In the first two sessions, a correction method was employed. The 16 subjects were divided at random into two groups. One was reinforced when jumping to the horizontal bar, the other to the vertical one. All rats were trained for 15 sessions on this problem, although all required between five and 
seven sessions to reach criterion $(80 \%$ correct responses in two consecutive sessions).

After this training, the subjects were divided into three groups: normal $(N)(N=6)$, triate monocular field $(S T)(N=5)$, and lateral peristriate (LP) $(\mathrm{N}=5)$. Preoperatively, there were no significant differences in performances of these three groups.

\section{Surgical Procedure}

Surgery was accomplished as soon as each rat completed 15 training sessions. All operations were performed under Nembutal anesthesia (40 mg/kg IP). Aseptic precautions were taken. Thermocoagulation of the cortex was done with a soldering tool with a $0.5-\mathrm{mm}$ tip diameter. The temperature was regulated by a variable transformer. The minimal lesion produced with this tool was about $.5-1.0 \mathrm{~mm}$ in diameter, with no perceptible damage to the white matter. Several contiguous small lesions were made in the cortex of the operated animals. In the LP group, the intent was to damage the group of lateral peristriate areas: anterolateral, lateromedial, laterolateral, and posterolateral areas, with the exception of the posterior area. In the ST group, the target was the monocular field of this area.

\section{Postoperative Training}

Directionality discrimination retention test. Retention capacity of the operated and normal control groups on the verticalhorizontal bar discrimination test was assessed by submitting the animal to a 20 -trial session test, 30 days after completion of the original training.

Conditional discrimination task. The conditional discrimination task consisted of two pattern discrimination problems followed by a conditional test session which combined pairs of stimuli of the last two problems. The discriminanda were similar to, but not identical with, the ones used by Lashley (1938) and North et al. (1958). For Task A, the stimulus cards were a white equilateral, erect (e) triangle vs. an inverted (i) one $(9.8 \mathrm{~cm}$ to a side) on a black (b) background (eb and ib, respectively). In Task $B$, the figures were identical to those in Task $\mathrm{A}$, but the background consisted of black and white stripes (s) $\left(1 \mathrm{~cm}\right.$ wide, $45^{\circ}$ angle) (es and is). Half of the subjects were trained on the task sequence $\mathrm{A}-\mathrm{B}$, the other half on B-A. In the first task, whether A or B, the inverted triangle was positive; in the second, the erect one. No provision was made to duplicate groups in order to balance the triangle orientation in either task, since according to our experience (unpublished data) the rat shows no preference for either of the triangle orientations used. The subjects were trained on each problem in daily 20-trial sessions to a criterion of at least $80 \%$ correct responses in each of 2 consecutive sessions or for a maximum of 36 sessions. During the first 2 sessions, a correction method was used.

Conditional test. After the subjects learned both problems, they were given a conditional discrimination test. Each subject was presented with two new combinations of the previous test cards. The paired cards were identical in their figure component but differed in their background. A new test pair consisted of the positive card in one task paired with the negative card in the other. For example, for half of the subjects, one test pair was ib + vs. is - and the other was es + vs. eb-. The two pairs of stimuli were presented in a random order.

The criterion of success was at least eight correct responses for each of the two combinations in one session of 20 trials. Those subjects not reaching criterion in the first test were retrained with the same procedure on the sequence of tasks A-B or B-A and the conditional test was repeated. A maximum of four conditional tests was presented.

\section{Histology}

After completion of the experiment, the operated animals were anesthetized and perfused through the heart with normal saline followed by $10 \%$ saline-Formalin solution. The brains were photo- graphed and the prints enlarged for reconstruction of the lesion. Frozen coronal sections were cut at $30 \mu$. Every sixth section was stained with cresyl violet and examined for extent of cortical lesion and retrograde degeneration in the dorsal lateral geniculate nuclei.

\section{RESULTS}

\section{Histology}

Lesions of the striate group of rats were restricted to the striate cortex. No significant damage to the white matter was noted. Intense retrograde degeneration was present in the region of the monocular field representation in the dLGN (Montero, Brugge, $\&$ Beitel, 1968). One animal, R12 of the ST group, was eliminated, since the lesion was laterally displaced impinging upon the binocular field representation of the striate cortex. The lateral peristriate group had the lesions restricted to the lateral peristriate cortex. The lesions appeared to involve the anterolateral, lateromedial, and laterolateral areas of the peristriate cortex (Montero et al., 1973). Retrograde degeneration in the dLGN nucleus was scanty or not demonstrable (Figure 1).

\section{Behavioral Results \\ Directionality Discrimination Retention Test}

No deficit was found in the retention of normal and operated subjects on the vertical-horizontal bar discrimination ( $N$ vs. $L P$ and $N$ vs. $S T: t=2$, $\mathrm{df}=9, \mathrm{p}>.05 ; \mathrm{ST}$ vs. LP: $\mathrm{t}=2.1, \mathrm{df}=8$, $p>.05)$. Within groups, comparisons were also statistically nonsignificant $(\mathrm{t}=2.3$ and 2.55 , df $=4$, $p>.05$ ) for LP and ST groups, respectively. Thus, no significant impairment was induced by the different experimental procedures on the retention test (Table 1).

\section{Conditional Discrimination}

Table 2 indicates for each individual the total number of trials to criterion required for task A plus B, on the original learning and on each relearning, if required. Comparison between the groups in terms of trials to reach criterion on original learning performance indicates that $\mathrm{N}$ and $\mathrm{ST}$ groups did not differ significantly in the number of trials for acquisition of the habit $(\mathrm{t}=1.02$, df $=9, \mathrm{p}>.05)$. However, there were significant differences between $\mathrm{N}$ vs. LP groups $(\mathrm{t}=4.19, \mathrm{df}=9, \mathrm{p}<.01)$ as well as for ST vs. LP ( $\mathrm{t}=2.96, \mathrm{df}=8, \mathrm{p}<.05)$. Pattern discrimination was more rapidly acquired for $\mathrm{N}$ and ST groups in relation to the LP group. Also, comparison between groups on the basis of total trials on the first relearning was made. There were no significant differences for either $\mathrm{N}$ vs. ST or ST vs. LP groups. However, there were overall differences for the $\mathrm{N}$ vs. $\mathrm{LP}$ comparison $(\mathrm{t}=4.23$, $\mathrm{df}=7$, 
ST
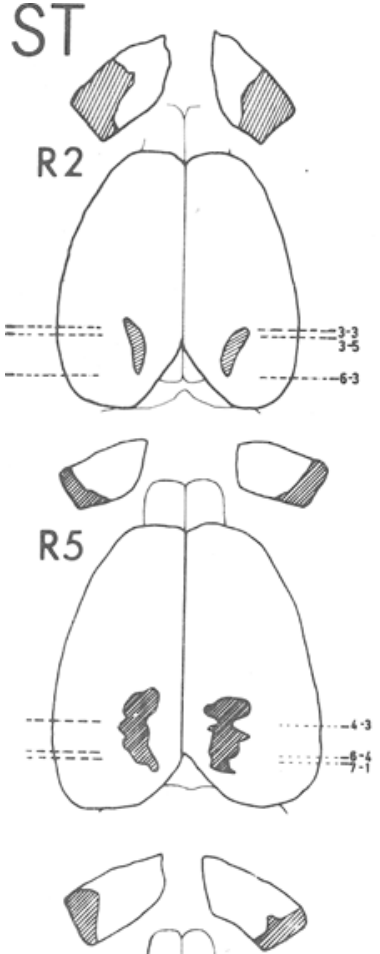

$\mathrm{R} 18$
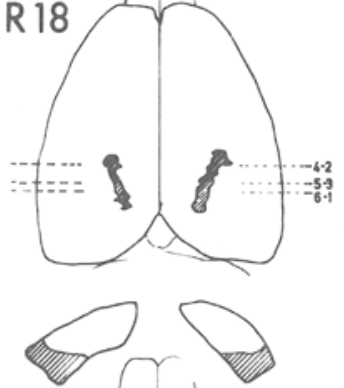

R 19
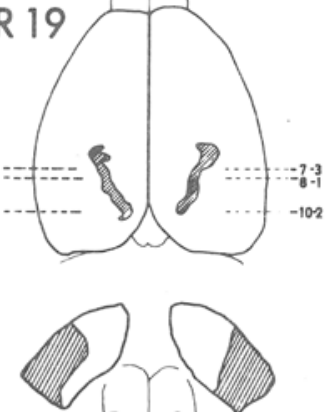

R 47

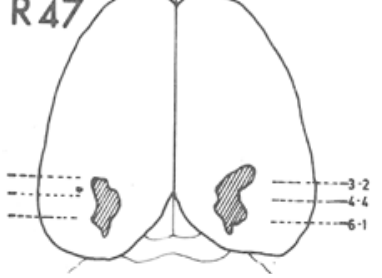

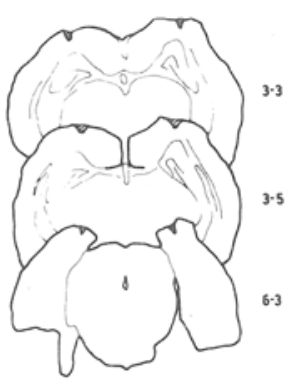

LP
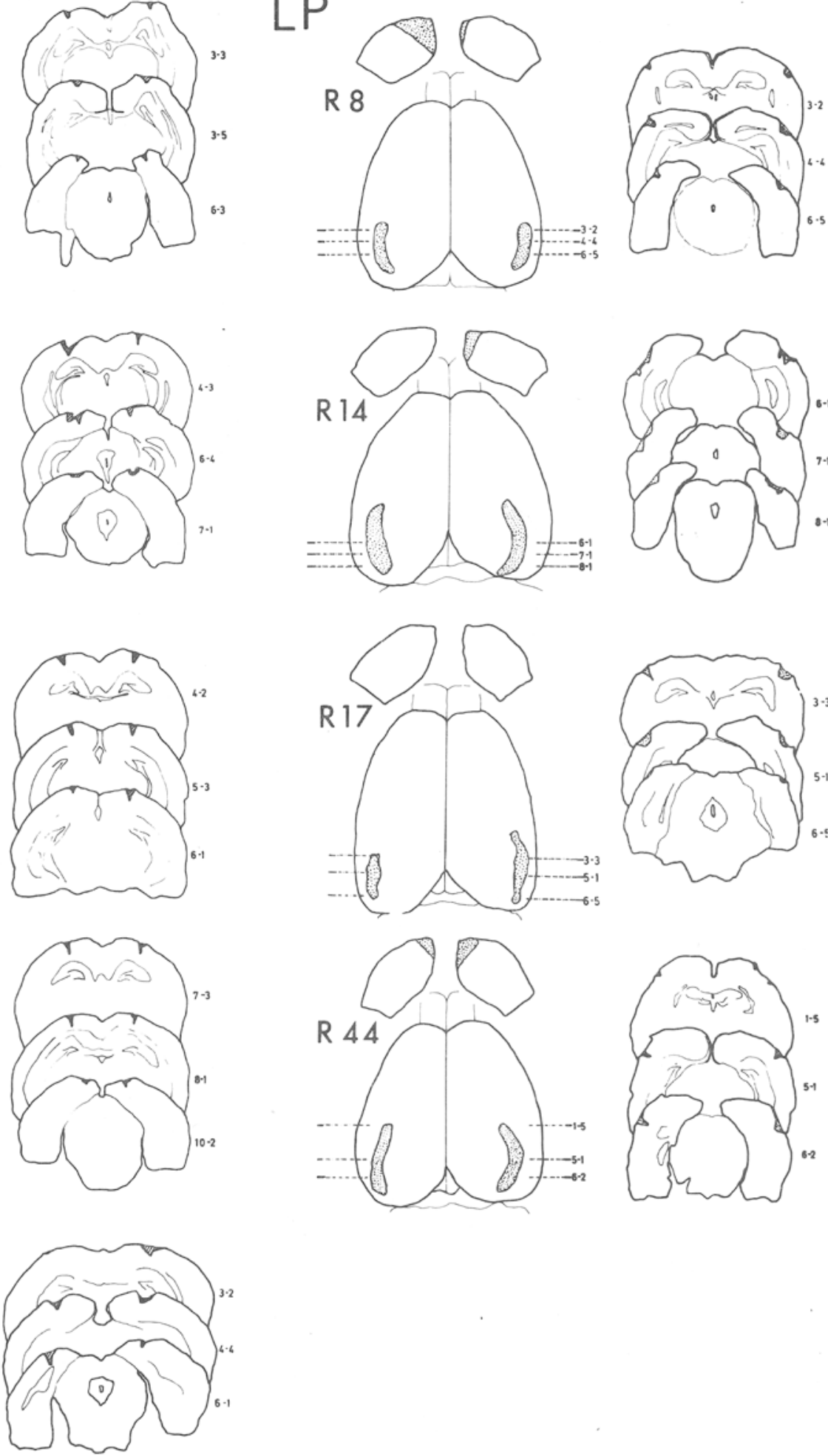
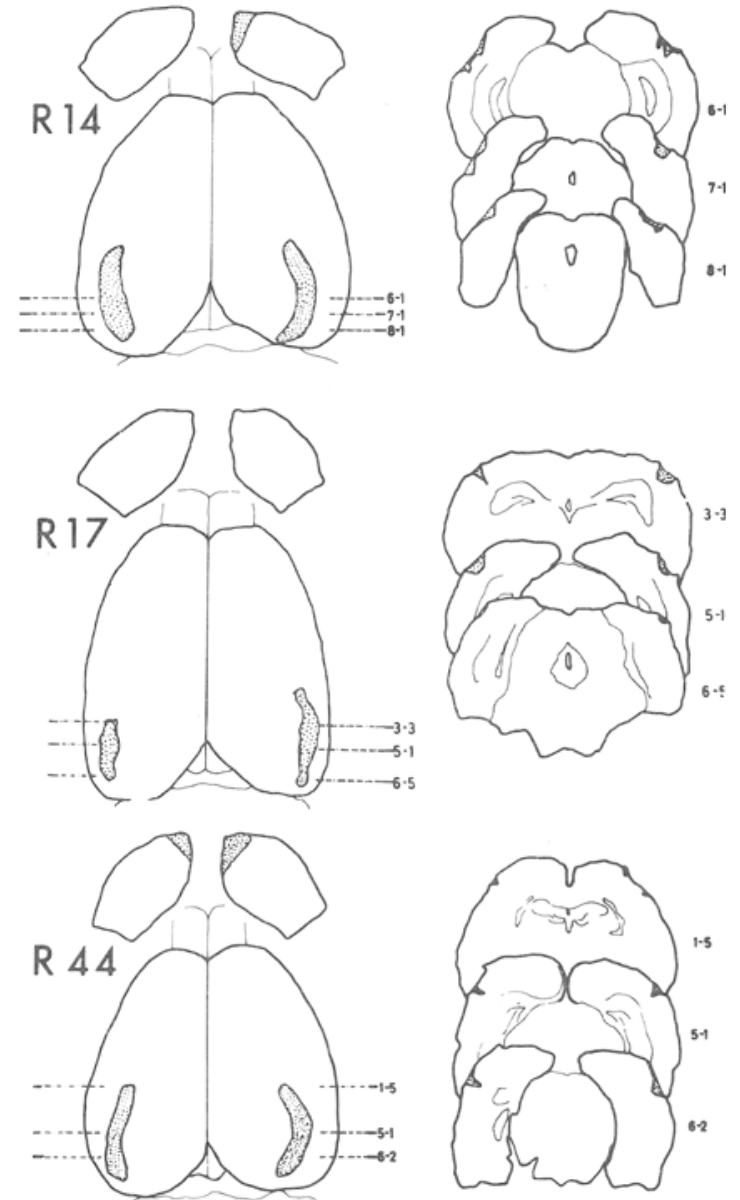

Figure 1. Diagrams of dorsal views and representative cross sections of the brains of operated subjects. The extents of the cortical lesions of the striate rats (ST) are indicated by hatching, those of the peristriate subjects (LP) by stippling. The corresponding degenerations in dLGN are similarly indicated. 
Table 1

Mean Number of Correct Responses for Each Group During the 15th Original Training Session and Retention Test in the Vertical vs. Horizontal Discrimination Task

\begin{tabular}{cccc}
\hline Group & N & $\begin{array}{c}\text { 15th } \\
\text { Session }\end{array}$ & $\begin{array}{c}\text { Retention } \\
\text { Test }\end{array}$ \\
\hline N $^{*}$ & 6 & 19.8 & 19.6 \\
St & 5 & 20.0 & 17.8 \\
LP & 5 & 20.0 & 16.8 \\
\hline
\end{tabular}

*30-day interval

Table 2

Trials to Criterion for Task A plus Task B for Each Rat on Successive Presentations of the Task

\begin{tabular}{|c|c|c|c|c|c|}
\hline \multicolumn{2}{|c|}{ Subject } & $\begin{array}{c}\text { Original } \\
\text { Learning }\end{array}$ & $\begin{array}{c}\text { First } \\
\text { Relearning }\end{array}$ & $\begin{array}{l}\text { Second } \\
\text { Relearning }\end{array}$ & $\begin{array}{c}\text { Third } \\
\text { Relearning }\end{array}$ \\
\hline $\mathrm{N}$ & $\begin{array}{l}1^{*} \\
3 \\
4 \\
11^{*} \\
13^{*} \\
16\end{array}$ & $\begin{array}{l}333 \\
306 \\
273 \\
333 \\
580 \\
360\end{array}$ & $\begin{array}{r}135 \\
\\
84 \\
170 \\
85\end{array}$ & 107 & 87 \\
\hline St & $\begin{array}{l}2^{*} \\
5^{*} \\
18 \\
19^{*} \\
47\end{array}$ & $\begin{array}{l}392 \\
610 \\
307 \\
545 \\
343\end{array}$ & $\begin{array}{l}147 \\
396 \\
174 \\
418 \\
120\end{array}$ & 320 & 207 \\
\hline LP & $\begin{array}{c}6^{*} \\
8^{*} \\
14 \\
17 \\
44\end{array}$ & $\begin{array}{l}664 \\
927 \\
688 \\
745 \\
506\end{array}$ & $\begin{array}{l}248 \\
540 \\
512 \\
453 \\
251\end{array}$ & $\begin{array}{c}87 \\
803 \dagger \\
289 \\
93 \\
203\end{array}$ & $\begin{array}{r}89 \\
\\
144 \\
126 \\
224\end{array}$ \\
\hline
\end{tabular}

*Animal started with Task A. †Animal failed to reach criterion in 36 sessions.

$\mathrm{p}<.05)$. Thus, the LP group still presented a deficit, in spite of the fact that these subjects had already met learning criterion on tasks $A$ and $B$.

Within groups, comparison of original and first relearning $(\mathrm{A}+\mathrm{B})$ indicates significant saving for all groups. Only for the LP group was it possible to compare total trials to criterion (tasks A + B) on the first, second, and third relearning. There were significant differences between first relearning vs. second $(\mathrm{t}=4.05, \mathrm{df}=4, \mathrm{p}<.05)$ but not between second vs. third ( $\mathrm{t}=1.55$, df $=3, \mathrm{p}>.05)$ or between first and third relearning $(\mathrm{t}=2.75$, $\mathrm{df}=3$, $\mathrm{p}>.05)$.

The relative difficulty of task A vs B is noteworthy. Thus, for all animals, 1,233 trials were required to reach criterion on task $A$, when $A$ was the starting problem; 2,081 trials were required for learning task $B$ when the latter was the first problem run. Hence, the learning of task $\mathrm{B}$ was significantly more difficult $(\mathrm{t}=2.6, \mathrm{df}=14, \mathrm{p}<.05)$.

Another question is whether the sequence of the task presented was relevant. The total number of trials for the A-B sequence were 1,233 and 3,151, respectively, while for the B-A sequence the figures were 2,081 and 1,447 . The differences were not significant $(\mathrm{t}=.67$ and 1.79, df $=14, \mathrm{p}>.05)$ for tasks $\mathrm{A}$ and B. We conclude that no demonstrable negative or positive transference of one particular task over the other was demonstrated. Table 3 indicates the number of subjects that reached criterion in successive conditional tests. The Fischer-Yates test yielded a significant difference between LP vs. N and ST groups $(p<.05)$. It can be concluded that only normal and striate subjects succeeded in the conditional discrimination task. Rat 5 of the ST group was the only one in that group that did not reach criterion after the 4th conditional test. No overall differences were found between the normal and striate subjects in the rate of learning in terms of trials to criterion $(\mathrm{t}=1.98, \mathrm{df}=9, \mathrm{p}>.05)$. Briefly, the results indicate that LP subjects were able to discriminate patterns, but required more trials to criterion than the $\mathbf{N}$ and ST groups. They failed to master conditional discrimination.

\section{DISCUSSION}

The results obtained demonstrated that lesions confined to lateral peristriate cortex profoundly alter the rat's capacity to learn a pattern and to succeed in a conditional discrimination task. On the other hand, they can postoperatively retain a directionality discrimination test (vertical-horizontal bar). Judging from the small change in the dLGN, we can conclude that the deficit is not due to damage of the geniculostriate system. The alterations in performance are apparently the results of destruction of one or more of the lateral peristriate areas. Of the five lateral areas described (Montero et al., 1973), only the posterior area appears spared in our LP rats. It was not expected that these rats would show a deficit on pattern discrimination. The notion generally accepted in this respect is that the striate cortex is the only cortical area involved in pattern discrimination, though in many studies lesions have extended into the peristriate cortex. Our results are at variance with this idea; in other words, other areas such as lateral peristriate cortex appears to participate in visual information processing. Negative results on striate (monocular field) lesioned animals are in line with previous work on rats. Lashley (1931,

Table 3

Number of Subjects that Reached Criterion at Each Conditional Test

\begin{tabular}{cccccc}
\hline & & \multicolumn{4}{c}{ Conditional Test } \\
\cline { 3 - 6 } Group & N & 1 & 2 & 3 & 4 \\
\hline N & 6 & 2 & 3 & & 1 \\
St & 5 & & 3 & & 1 \\
LP & 5 & 0 & 0 & 0 & 0 \\
\hline
\end{tabular}

Note-One subject in the St group did not meet criterion. 
1939) reported that partial striate lesions do not affect the rat's capacity for pattern discrimination.

It is worth mentioning Murphy and Chow's (1974) results on the rabbit after striate and occipital lesions. They report negative results on pattern discrimination after lesions in Rose's (1931) area occipitalis, as opposed to a clear deficit after even partial lesions of the striate cortex. These discrepancies are worth mentioning, because recently Montero and Murphy (1976) have reported for the rabbit a pattern of corticocortical connections between striate and peristriate areas similar to that present in the rat. The rabbit's occipital lesions most certainly included lateral peristriate areas.

The failure of LP subjects on the conditional test was clear cut. Not one was able to learn it. Rat 5 of the striate (monocular field) group also failed; the difference in performance of this one subject with respect to its group could not be explained on histological grounds. Lateral peristriate rats were able to learn the two pattern discrimination tasks presented postoperatively, although with a deficit, so it can be concluded that they discriminate figure cues. The conditional test required, in addition, the association of figure and background, and this apparently they could not achieve. In conclusion, lateral peristriate rats showed a deficit in pattern discrimination and failed to integrate two visual cues, such as those used in the conditional task. These alterations cannot be ascribed to damage of the geniculostriate system. The above conclusion does not deny that severe damage to the binocular field of the striate cortex might lead to an impairment of pattern discrimination and failure on the conditional discrimination test. In fact, Rat 12 with such a lesion failed on the latter.

Two possible alterations at the visual level could account for the deficit presented by LP rats. The difficulty these rats had in discriminating between two figures with identical background and their failure to select the correct one, when this was contingent on the background, suggest an alteration of visual information processing. The pattern of connectivity of LP areas with the striate cortex gives a structural basis to this assumption. Another factor which might contribute to LP rats' deficit might be a change in the storage or retrieval mechanisms. These rats, after reaching criterion on the original learning of tasks A and B, still presented deficits on the first relearning with respect to the normal group, though there was a significant saving between original and first relearning. Further saving on successive relearning (2nd vs. 3rd vs. 1st) was not found, which again favors this interpretation. The normal retention by operated subjects on the horizontal-vertical test indicates that LP rats present a general behavior appropriate to the experimental situation; negative results in this respect might be due to preoperative training, to the fact that it was an easier task (unpublished data), and/or to overtraining on this task on the original learning.

\section{REFERENCES}

Bland, B. H., \& Cooper, R. M. Posterior neodecortication in the rat: Age of operation and experience. Journal of Comparative and Physiological Psychology, 1969, 69, 345-354.

BLAND, B. H., \& Cooper, R. M. Experience and vision of the posterior neodecorticate rat. Physiology \& Behavior, 1970, 5, 211-214.

Braun, J. J., Lundy, E. G., \& McCarthy, F. V. Depth discrimination in rats following removal of visual neocortex. Brain Research, 1970, 20, 283-291.

LASHLEY, K. S. The mechanism of vision. IV. The cerebral areas necessary for pattern vision in the rat. Journal of Comparative Neurology, 1931, 53, 419-478.

LASHLEY, K. S. Conditional reactions in the rat. Journal of Psychology, 1938, 6, 311-324.

LASHLEY, K. S. The mechanism of vision. XVI. The functioning of small remnants of the visual cortex. Journal of Comparative Neurology, 1939, 70, 45-67.

Montero, V. M. Evoked responses in the rat's visual cortex to contralateral, ipsilateral and restricted photic stimulation. Brain Research, 1973, 53, 192-196.

Montero, V. M., Bravo, H., \& Fernández, V. Striateperistriate corticocortical connections in the albino and gray rat. Brain Research, 1973, 53, 202-207.

Montero, V. M., Brugge, J. F., \& Beitel, R. E. Relation of the visual field to the lateral geniculate body of the albino rat. Journal of Neurophysiology, 1968, 31, 221-236.

Montero, V. M., \& MURPHY, E. H. Corticocortical connections from the striate cortex in the rabbit. Anatomical Records, 1976, 184, 483.

Montero, V. M., Rojas, A., \& Torrealba, F. Retinotopic organization of striate and peristriate visual cortex of the albino rat. Brain Research, 1973, 53, 197-201.

Murphy, E. H., \& CHOw, K. L. Effects of striate and occipital cortical lesions on visual discrimination in the rabbit. Experimental Neurology, 1974, 42, 78-88.

North, A. J., Maller, O., \& Hughes, C. Conditional discrimination and stimulus patterning. Journal of Comparative Physiological Psychology, 1958, 51, 711-715.

Rose, M. Zytoarchitektonischer Atlas der Grosshirnrinde des Kaninchens. Journal für Psychologie und Neurologie (Leipzig), 1931, 43, 353-440.

Sutherland, N. S., \& Mackintosh, N. J. Mechanism of animal discrimination learning. New York-London: Academic Press, 1971.

Thompson, V. E. Visual decortication in infancy in rats. Journal of Comparative and Physiological Psychology, 1970, 72, 444-451.

(Received for publication August 30, 1977; revision accepted January $23,1979$. ) 